\title{
COMPARISON OF CONTROL ALGORITHMS BY SIMULATING POWER CONSUMPTION OF DIFFERENTIAL DRIVE MOBILE ROBOT MOTION CONTROL IN VINEYARD ROW
}

\author{
Dušan HRUBÝ, Dušan MARKO, Martin OLEJÁR, Vladimír CVIKLOVIČ*, Dominik HORŇÁK \\ Slovak University of Agriculture in Nitra, Slovak Republic
}

\begin{abstract}
The paper deals with comparing electricity power consumption of various control algorithms by simulating differential mobile robot motion control in a vineyard row. In field of autonomous mobile robotics, the quality of control is a crucial aspect. Besides the precision of control, the energy consumption for motion is becoming an increasingly demanding characteristic of a controller due to the increasing costs of fossil fuels and electricity. A simulation model of a differential drive mobile robot motion in a vineyard row was created, including robot dynamics for evaluating motion consumption, and there were implemented commonly used PID, Fuzzy, and LQ control algorithms, the task of which was to navigate the robot through the centre of vineyard row section by measuring distances from trellises on both robot sides. The comparison was carried out using Matlab software and the best results in terms of both power consumption and control accuracy were achieved by LQI controller. The designed model for navigating the robot through the vineyard row centre and optimized controllers were implemented in a real robot and tested under real conditions.
\end{abstract}

Keywords: robot control; PID control; fuzzy control; optimal control; simulation; energy consumption

Nowadays, with continuously reducing fossil fuels supplies and increasing electricity prices as the demand for it increases, it is becoming necessary to consider, in addition to accuracy and speed, another condition for selecting the control algorithm - the energy consumption of control. Mei et al. (2005) presented a concept on how to reduce the energy consumption of components such as processors and sensors. However, depending on the robot size, the participation of components in total results in decreased consumption. Therefore, the main objective is to examine the consumption of actuators. Jaramillo and Gómez Mendoza (2018) compared the impacts of a mixed dynamic model incorporating both motor and robot chassis dynamics on driving characteristics and consumption to the model with only motor dynamics. This resulted in differences in consumption and more realistic behaviour of the mixed model. Furthermore, Jaramillo et al. (2020) proved that an accurate power model allows the estimation of energy consumption along different trajectories with over $90 \%$ accuracy. Wang et al. (2019) compared both the simulated and experimentally designed controller with its optimized version using the $\mathrm{H} \infty$ method on the omnidirectional robot model. The optimized controller achieved not only smaller control errors, but also lower robot power consumption. Tokekar et al. (2011) engaged in optimizing the speed profiles of the wheeled robot for the lowest possible consumption when moving on a flat track. They found that the lowest consumption was achieved with a parabolic speed profile. A direct comparison of mobile robot motion controllers was done by Stefek et al. (2020), who observed that the controllers with low energy consumption lacked accuracy due to their smooth control actions and vice versa accurate controllers showed to have a higher consumption. Recently, Beloev et al. (2021) created a prototype of an autonomous robot for precision agriculture potentially capable of various tasks. This type of robot equipped with complex location sensors capable of real-time trajectory planning is becoming a standard in precision agriculture and is a great platform for optimizing control with respect to reducing consumption.

The goal of this work is to compare power consumption and control precision in case of three commonly used control algorithms in a scenario of differential drive mobile robot movement in a vineyard row. The desired trajectory of robot is the row centre. Simulations are conducted with a mathematical model, including both dynamics and kinematics.

\section{Material and methods}

\section{Differential drive mobile robot}

The robot with differential chassis is a device with two independently driven wheels located on a common axis 
Table 1 Parameters of differential drive mobile robot mathematical model

\begin{tabular}{|c|c|c|c|}
\hline$K_{t}\left(\mathrm{~N} \cdot \mathrm{m} \cdot \mathrm{A}^{-1}\right)$ & $9 \cdot 10^{-2}$ & $m(\mathbf{k g})$ & 3 \\
\hline$K\left(\mathrm{~V} \cdot \mathrm{min}^{-1}\right)$ & $4.4 \cdot 10^{-2}$ & $I(\mathrm{~m})$ & 0.25 \\
\hline$R(\Omega)$ & 8 & $I_{T}(\mathrm{~m})$ & 0.05 \\
\hline$L(\mathrm{mH})$ & 2 & $J_{T}\left(\mathrm{~kg} \cdot \mathrm{m}^{-2}\right)$ & 0.056 \\
\hline$J\left(\mathrm{~kg} \cdot \mathrm{m}^{-2}\right)$ & $3.10^{-5}$ & $k_{v}\left(\mathrm{~kg} \cdot \mathrm{s}^{-1}\right)$ & 0.1 \\
\hline$k_{r}\left(\mathrm{~kg} \cdot \mathrm{m}^{2} \cdot \mathrm{s}^{-1}\right)$ & $6.3 \cdot 10^{-2}$ & $k_{\omega}\left(\mathrm{kg} \cdot \mathrm{m}^{2} \cdot \mathrm{s}^{-1}\right)$ & 1.3 \\
\hline$r(\mathrm{~m})$ & 0.05 & $p_{G}$ & 10 \\
\hline
\end{tabular}

$K_{t}$ - motor torque constant; $K$ - electric constant; $R$ - motor winding resistance; $L$ - motor inductance; $J$ - rotor moment of inertia; $k_{r}$ - coefficient of rotation resistance; $r$ - wheel radius; $m$ - robot mass; $I$ - half of track width; $J_{T}$ - moment of inertia in centre of gravity; $k_{v}$ - resistance coefficient against linear motion; $k_{\omega}$ - resistance coefficient against rotary motion; $p_{G}$ - gearbox gear ratio

perpendicular to the direction of rotation of wheels and often the third wheel, which is added for the robot stability (Tóth et al., 2017).

For the purposes of robot driving simulations using various control algorithms and examining their quality, including the robot consumption, it was decided to use a state-space mathematical model investigated by Dušek et al. (2011). In addition to the robot's kinematics, this model includes a dynamic part describing the dependence of electric currents on the load and wheel velocities from the supplied motor voltages, respecting the dynamics of engine, construction, geometry and other parameters of chassis and engines. Parameters for the robot model observed are stated in Table 1 and were selected to approximate a real mobile robot EN20 described by Cviklovič et al. (2016).

\section{Control algorithms}

As for the control algorithms, there were selected three of the most commonly used - PID (proportional-integral-derivative), Fuzzy, and LQ (linear-quadratic) controllers.

\section{PID (PSD) controller}

For the most accurate simulation results, a discrete form of PID controller was employed - PSD (proportional-sum-derivative) controller, which is necessary for simulating computer-controlled robot at a certain sampling rate. A parallel form of PSD controller is represented as follows:

$$
u(k)=K_{p} e(k T)+K_{i} T \sum_{k=0}^{n} e(k T)+K_{d} \frac{1}{T}[e(k T)-e((k-1) T)]
$$

where:

$u(k)$ - control action; $e(k T)$ - control error; $T$ - sampling time (s); $K_{p}$ - proportional gain; $K_{i}$ - integral gain $\left(\mathrm{s}^{-1}\right) ; K_{d}$ - derivative gain $(\mathrm{s}) ; k$ - sample number

\section{Fuzzy controller}

Controller based on fuzzy logic provides a solution for linguistic terms such as "much", "medium", "little", etc. It enables the conduction of processes of human

Table 2 Linguistic variables for input and output quantities $v_{R^{\prime}} \theta_{e^{\prime}} u_{p^{\prime}} u_{L}$

\begin{tabular}{|c|c|c|}
\hline$v_{R}\left(\mathrm{~m} \cdot \mathrm{s}^{-1}\right)$ & $\theta_{e}(\mathrm{rad})$ & $u_{p}, u_{L}$ (value) \\
\hline - very slow & - too left & - slow down more (0) \\
\hline - slow & - left & - slow down (0.25) \\
\hline - desired & - desired & - optimal (0.5) \\
\hline - fast & - right & - speed up (0.75) \\
\hline - very fast & - too right & - speed up more (1) \\
\hline
\end{tabular}

decision-making in algorithmic form and is based on a qualitative description of the dynamic system. Its main advantage is that there is no need to know the mathematical description of a system for its implementation (Hrubý and Amrich, 2008). The fuzzy sets theory is based on a membership degree of elements to the set. The value of each element in set is between 0 and 1 (Cviklovič et al., 2016). Table 2 shows selected linguistic variables for the fuzzy controller observed. For shorter computational time, Sugeno fuzzy system with constant output membership functions was employed (Table 2 - in brackets). It represents 25 combinations in total for inference rules.

\section{LQ controller}

When dealing with consumption and control efficiency, LQ controller should be taken into consideration as a representative of optimal control. A detailed description of LQ controller and the effects of its weighting matrices $Q$ and $R$ were presented by Khatoon et al. (2014). This investigation opted for a variation of LQ controller with added integration component that improves the controller response when additional external forces act on the system - LQI (linear-quadratic-integral) controller. Using the integration component, the $Q$ and $K$ matrices can be extended by the number of output vector states and the integration component impact can be penalised by adjusting the related elements of the $Q$ matrix. A feedback law for LQI controller is:

$$
u=-K\left[\begin{array}{l}
x \\
x_{i}
\end{array}\right]
$$

where:

$u$ - control variable $(\mathrm{V}) ; K$ - optimal gain matrix; $x$ - state vector $\left(A, A, \operatorname{rad} \cdot \mathrm{s}^{-1}\right.$, $\left.\mathrm{rad} \cdot \mathrm{s}^{-1}\right)^{T} ; x_{i}-$ integrator output $(\mathrm{m}$, $\left.\mathrm{rad} \cdot \mathrm{s}^{-1}\right)_{T}$

\section{Navigation algorithm}

Inputs to controllers represent measured distances from a vineyard wall on each side of the robot and the robot linear velocity. The robot position error e can be calculated as follows:

$$
e=d_{R}-d_{L}
$$


where:

$e$ - robot position error $(\mathrm{m}) ; d_{R}$ - distance from right vineyard row wall $(\mathrm{m}) ; d_{L}$ - distance from left vineyard row wall $(\mathrm{m})$

Since the target is not only the position error to be minimized, but also the robot orientation, a technique similar to the method presented by Khatoon (2014) was utilized to calculate desired robot orientation angle $\theta_{d}$ :

$$
\theta_{d}=\arctan \left(\frac{-e}{\Delta s}\right)=\arctan \left(\frac{-e}{v_{R} T}\right)
$$

where:

$\theta_{d}$ - desired robot orientation angle (rad); $T$ - sample time $(\mathrm{s}) ; \Delta s$ - distance travelled over time $T(\mathrm{~m})$

A more demonstrative representation of this method is provided in Fig. 1.

The second input to a controller is velocity error $e_{v}$ (Eq. 5). The desired velocity $v_{w}$ was constant for the purposes of this research.

$$
e_{v}=v_{w}-v_{R}
$$

where:

$e_{v}-$ robot velocity error $\left(\mathrm{m} \cdot \mathrm{s}^{-1}\right) ; v_{w}$ - desired speed $\left(\mathrm{m} \cdot \mathrm{s}^{-1}\right)$; $v_{R}$-actual robot speed $\left(\mathrm{m} \cdot \mathrm{s}^{-1}\right)$

Finally, the robot orientation angle error $\theta_{e}$ entering the controller is visualized in Fig. 2 and can be calculated using Eq. 6:

$$
\theta_{e}=\theta_{d}-\theta_{R}
$$

where:

$\theta_{e}$ - robot orientation angle error $(\mathrm{rad}) ; \theta_{R}-$ actual robot orientation angle (rad)

For the LQI controller, as its integrational matrix $x_{i}$ requires to have same quantities as the robot's state space model output vector $y$, it was required to calculate robot's angular velocity error $\omega_{e}$ (Eq. 7). Desired angular velocity of robot $\omega_{d}$ can be calculated using Eq. 8:

$$
\omega_{e}=\omega_{d}-\omega_{R}
$$

where:

$\omega_{e}$ - robot's angular velocity error; $\omega_{d}$ - desired angular velocity $\left(\mathrm{rad} \cdot \mathrm{s}^{-1}\right) ; \omega_{R}-$ actual angular velocity of robot $\left(\mathrm{rad} \cdot \mathrm{s}^{-1}\right)$

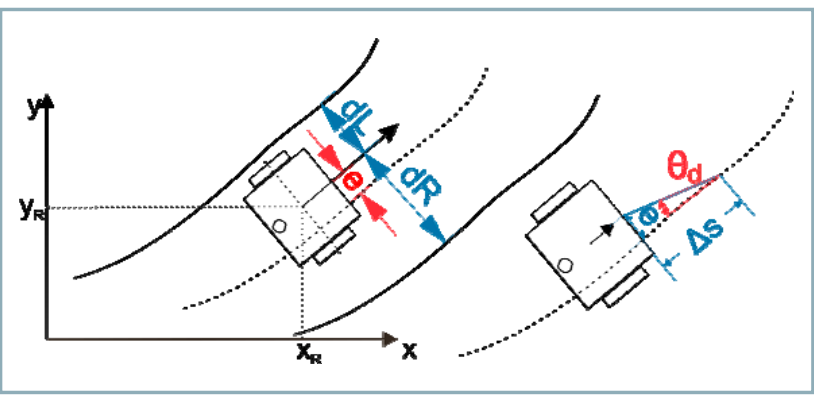

Fig. 1 Determination of desired robot orientation angle $\theta_{d}$

$$
\omega_{d}=\frac{\Delta \theta_{d}}{T}=\frac{\theta_{d}-\theta_{d_{-1}}}{T}
$$

where:

$\theta_{d-1}-$ previous desired orientation angle of robot (rad)

\section{Control quality criterions}

Control quality was based on monitoring the mobile robot performance along the test track.

\section{Absolute control error area}

The absolute control error area $I_{A E}$ (Eq. 9) gives basic information on controller's ability to track the desired trajectory. This criterion is applicable for both oscillating and non-oscillating control processes.

$$
I_{A E}=\int_{0}^{\infty}|e(t)| d t
$$

\section{Average control error}

The average control deviation is calculated as proportion of the absolute control area to the distance travelled by the robot:

$$
e_{\text {avg }}=\frac{I_{A E}}{d}
$$

where:

$e_{\text {avg }}$ - average control error; $d$ - distance travelled by robot (m)

\section{Smoothness of curvature}

To quantify how smooth is the robot movement, Smoothness of Curvature (Smoo) metric was utilized (Munoz-Ceballos and Valencia-Velasquez, 2014):

$$
\text { Smoo }=\frac{\int_{0}^{1}\left(\frac{d \kappa}{d t}\right)^{2} d s}{t}
$$

where:

$\kappa$ - trajectory curvature $\left(\mathrm{m}^{-1}\right) ; s-$ trajectory length $(\mathrm{m})$; $t$ - simulation time (s)

Due to the operation in a discrete environment, integration was approximated by trapezoidal numerical

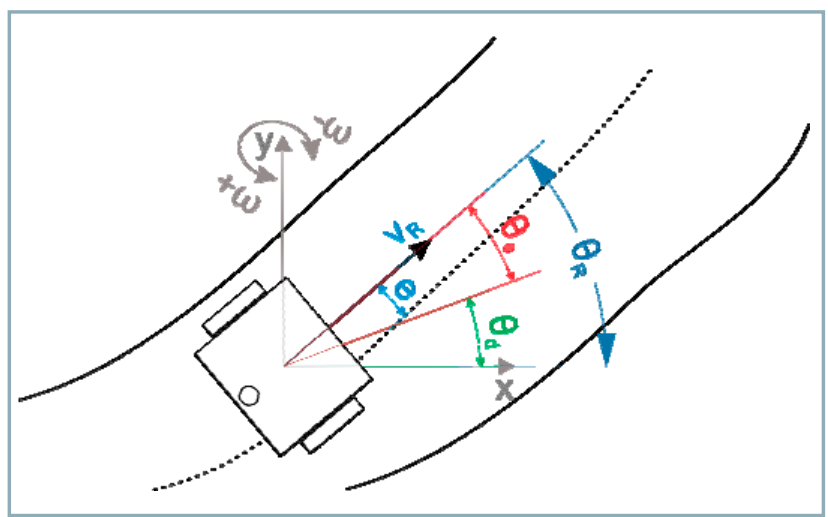

Fig. 2 Calculation principle of robot orientation angle error $\theta_{e}$ 
method. For trajectory curvature calculation, open source Matlab code created by Dirk-Jan (2011) was employed.

\section{Electricity consumption calculation}

The mobile robot's own consumption $\mathrm{W}$ was calculated based on the instantaneous power $P$ for each motor. Consumption was evaluated as the sum of all instantaneous power values:

$$
W=\sum_{0}^{t} P(k T) T=\sum_{0}^{t}[u(k T) \times i(k T)] T
$$

where:

$P$ - instantaneous power (W); $u$ - motor input voltage calculated by controller $(\mathrm{V}) ; i$ - electric current; $T$ - sampling time (s)

\section{Results and discussion}

The simulation model was created and evaluated in Matlab Simulink software. There were created all controllers with a sampling period of $T=0.1 \mathrm{~s}$ in order to more realistically simulate the numerical controller's behaviour. The desired tangential speed $v_{R}$ was $0.5 \mathrm{~m} \cdot \mathrm{s}^{-1}$ for all simulations. Considering the distance sensor simulation, the results used came from previous research (Marko and Hrubý, 2020), which compared 3 different distance sensors for measuring distance in vineyard row. A simplified simulation flowchart of the Simulink model is shown in Fig. 3, highlighting the quantities calculated; the simulation model itself is shown in Fig. 4. Testing track design, distance sensor characteristics and their placement on the robot were performed in the Matlab Driving Scenario Designer toolbox. All the quantities required to be calculated by integrating were approximated by the trapezoidal numerical method at a given sample time

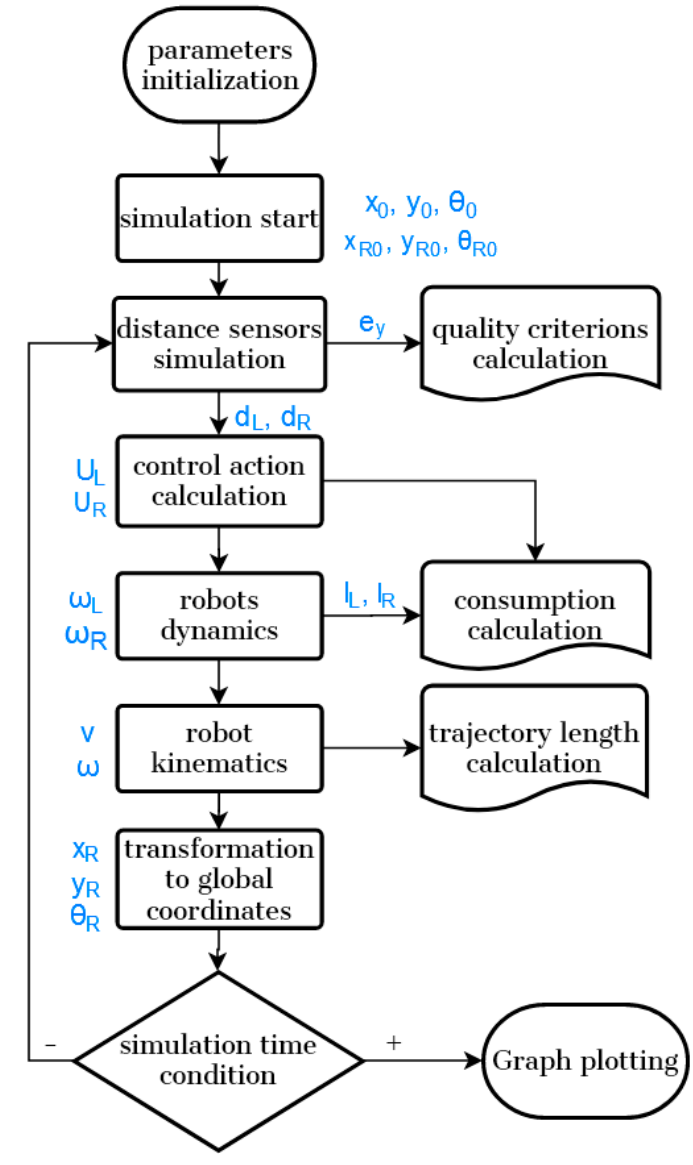

Fig. 3 Simulation scenario flowchart

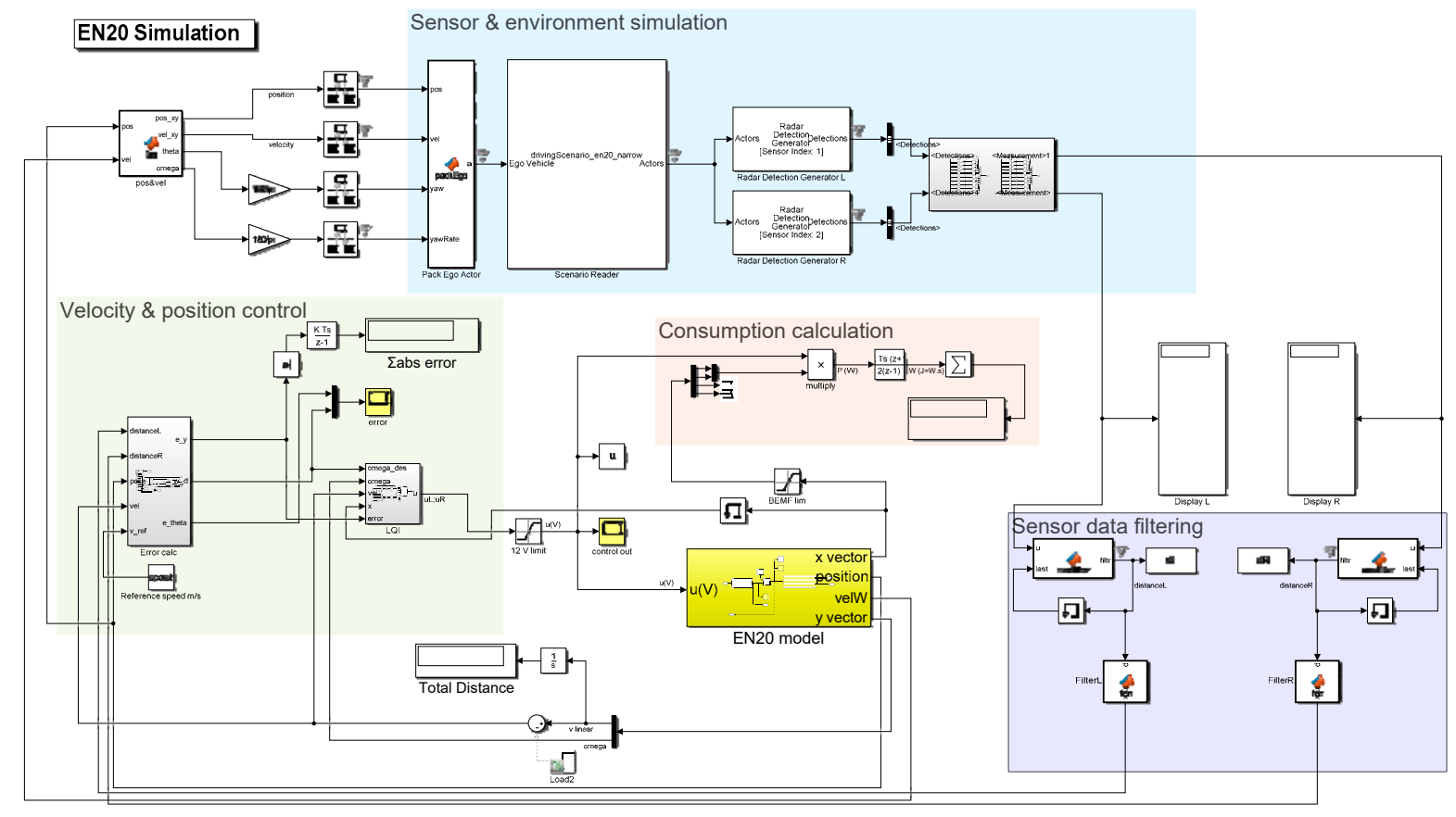

Fig. 4 Simulink simulation model 
in order to be more realistic. Since a simulated mobile robot is a MIMO (multiple-input and multiple-output) system with 2 inputs and 2 outputs, it was necessary to create 2 PSD controllers, each for one input quantity. To transform the control action of each controller into control actions for the robot's motors, Eq. 13 was created - it determines the voltage supplied to each motor taking into account the radius and a track width of the robot:

$$
u_{p}=u_{v}+\frac{u_{p o s} \times I}{2 r}, \quad u_{L}=u_{v}-\frac{u_{p o s} \times I}{2 r}
$$

where:

$u_{P}$ - voltage supplied to right motor $(\mathrm{V}) ; u_{L}$ - voltage supplied to left motor $(\mathrm{V}) ; u_{v}$ - velocity controller control action $(\mathrm{V})$; $u_{\text {pos }}$ - position controller control action (V)

To set the parameters of both controllers, the possibility of automatic tuning of the PID block in Simulink was utilized. It was striven to achieve the shortest possible time to obtain the desired values without overshooting the setpoint. The parameters obtained are in Table 3.

Table 3 Tuned constants of PID (PSD) controller

\begin{tabular}{|l||c|c|}
\hline Constant & Velocity controller & Position controller \\
\hline $\boldsymbol{K}_{\boldsymbol{P}}$ & 2.9877 & 5.9199 \\
\hline $\boldsymbol{K}_{\boldsymbol{I}}$ & 29.8773 & 0.6960 \\
\hline $\boldsymbol{K}_{\boldsymbol{D}}$ & 0.0747 & 1.1792 \\
\hline
\end{tabular}

Using PSD control, the robot motion trajectory is shown in Fig. 5 and the time courses of the input voltages to engines and the output vector in Fig. 6 . It can be observed that the PSD controller was able to quickly suppress the control deviation and lead the robot relatively well through the track centre, however, the course of the input voltages and angular velocity values indicate that the robot movement was not very smooth (Table 4).

Fuzzy controller was designed using the Matlab Fuzzy Logic Designer toolbox. Since the fuzzy controller allows the control of MIMO systems, it is enough to create a single controller for the overall robot control. Based on the linguistic variables in Table 2, triangular input membership

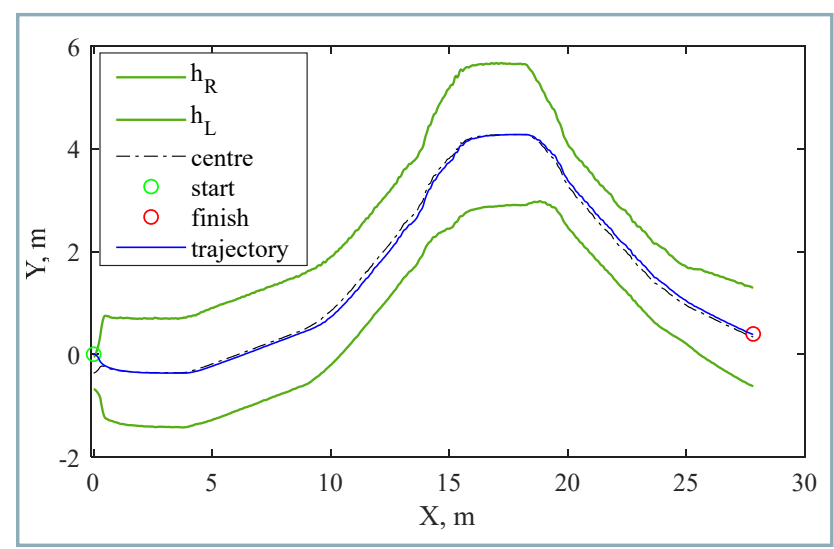

Fig. 5 PSD control trajectory

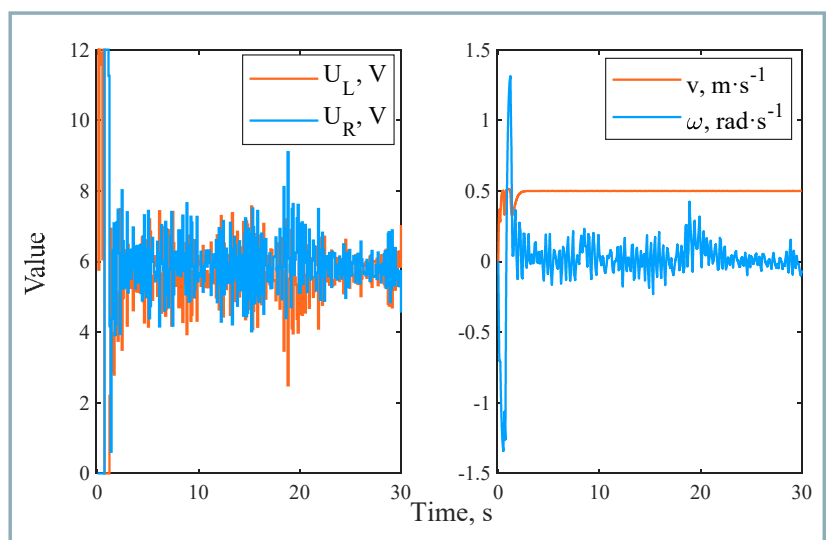

Fig. 6 Time courses of input voltages and output vector utilizing PSD control

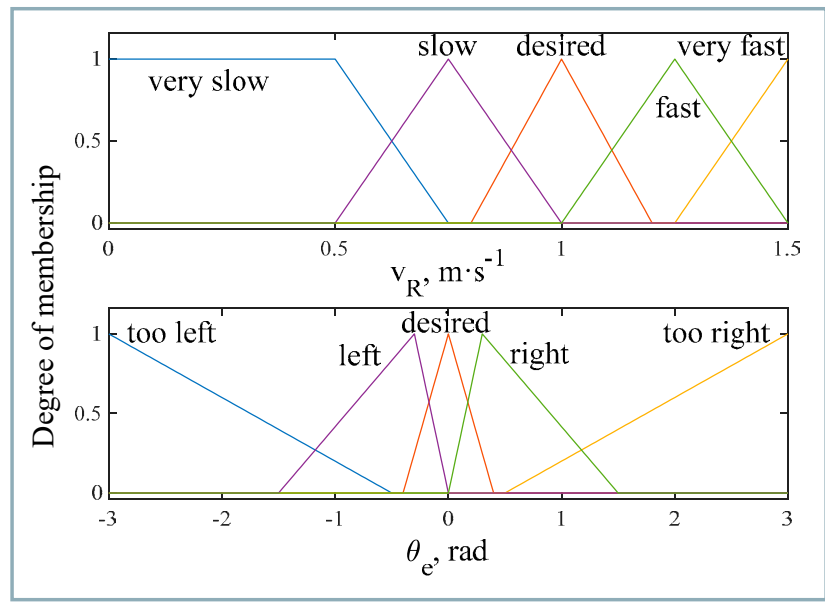

Fig. 7 Membership functions for robot velocity and robot orientation angle

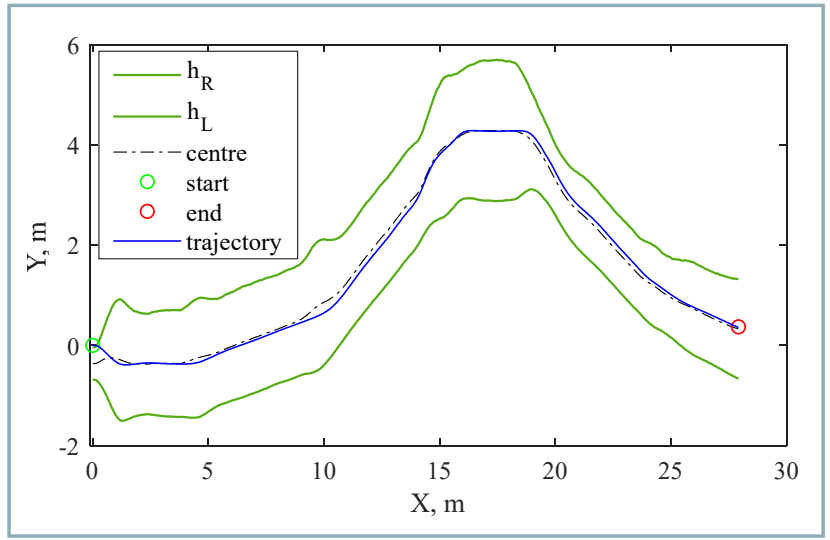

Fig. 8 Fuzzy control trajectory 


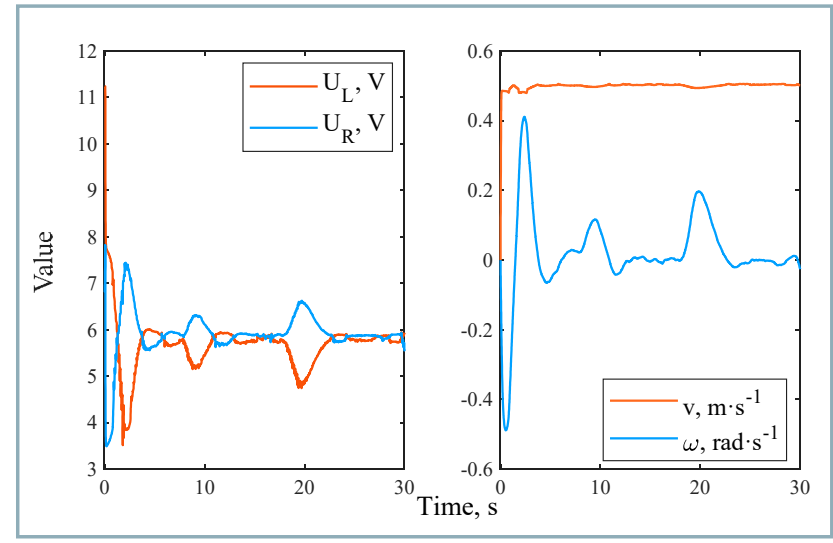

Fig. 9 Time courses of input voltages and output vector using fuzzy control

functions were established (Fig. 7). Using fuzzy control, the trajectory is shown in Fig. 8 and the time courses of the input voltages to engines and the output vector in Fig. 9.

The appropriate matrix of optimal gain $K$ was determined by trial-and-error method by adjusting the diagonal matrix $Q$ parameters. Matrix $R$ was determined in the beginning. The controller showed the best results for the parameters in Eq. 14. In this case, by increasing the value of parameters, the weights of associated state variables were reduced and vice versa. Using LQI control, the trajectory is shown in Fig. 10 and the time courses of the input voltages and output state vector in Fig. 11. The overall results of controllers for all specified quality criteria are given in Table 4.

$$
Q=\left(\begin{array}{cccccc}
4 & 0 & 0 & 0 & 0 & 0 \\
0 & 4 & 0 & 0 & 0 & 0 \\
0 & 0 & 0 & 0 & 0 & 0 \\
0 & 0 & 0 & 0 & 0 & 0 \\
0 & 0 & 0 & 0 & 80 & 0 \\
0 & 0 & 0 & 0 & 0 & 20
\end{array}\right) ; \quad R=\left(\begin{array}{cc}
0.1 & 0 \\
0 & 0.1
\end{array}\right)
$$

Based on the results obtained, the LQI controller showed the best performance in terms of all assessed parameters, except for the distance travelled, which was lower by $0.3 \mathrm{~m}$ than the average results of the other two controllers. This is due to the smoother robot acceleration using this controller, which was also reflected by the lowest consumption achieved. Based on a comparison of inputs and outputs of controllers in Figs 6, 9 and 11, it is possible to conclude that the lowest power consumption of LQI controller $W=$ 291.8 W.s was due to the smoothest changes in controller outputs with $S m o o=0.0118 \mathrm{~m}^{-1} \cdot \mathrm{s}^{-3}$. Furthermore, the LQI controller also came out as the best in terms of position

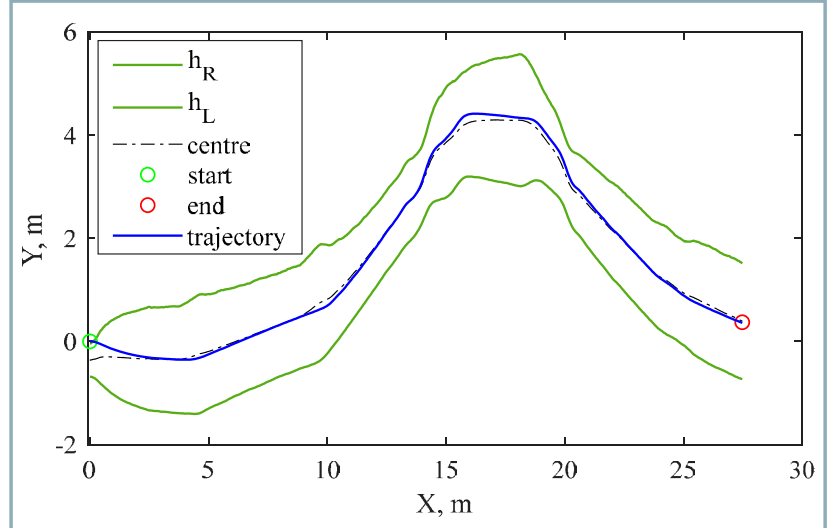

Fig. 10 LQI control trajectory

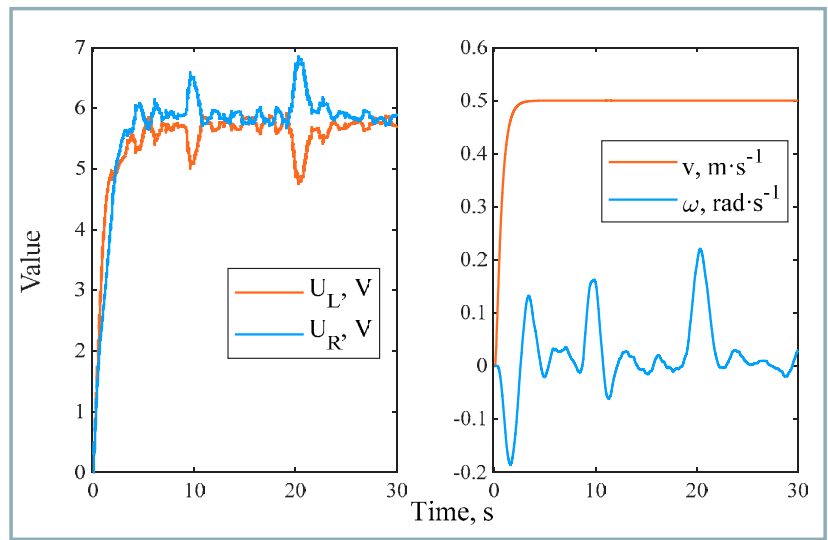

Fig. 11 Time courses of input voltages and output vector using LQI control

control precision based on $I_{A E}=4.339 \mathrm{~m}$ and $e_{\text {avg }}=0.146$, which is in contrast with the comparison carried out by Stefek et al. (2020), in which the compared controllers were either energy-efficient or precise, but not both.

\section{Conclusions}

The results presented brought a comparison of the most popular feedback control algorithms in terms of not very frequently observed criterion of energy consumption of actuators. The functionality of proposed controllers was experimentally verified on the real robot and the differences between simulations and real experiments were assessed. When the issues in control were observed, there were taken measures to further optimize the control algorithms for the lowest possible consumption. It is expected that the greatest differences to simulations are due to the character of surface on which the test was conducted. In the simulations presented, the surface was considered to be

Table 4 The resulting comparison of motion control by individual controllers

\begin{tabular}{|c|c|c|c|c|c|c|}
\hline Controller & $\begin{array}{c}\text { Travelled } \\
\text { distance }(\mathbf{m})\end{array}$ & $W(\mathbf{W} \cdot \mathbf{s})$ & $\begin{array}{l}\text { Consumption } \\
\text { difference }(\%)\end{array}$ & $\begin{array}{l}I_{A E} \\
(\mathrm{~m})\end{array}$ & $\begin{array}{c}\text { Smoo } \\
\left(\mathrm{m}^{-1} \cdot \mathrm{s}^{-3}\right)\end{array}$ & $e_{\text {avg }}$ \\
\hline PSD & 29.87 & 303.2 & 0 & 4.865 & 2.5215 & 0.163 \\
\hline Fuzzy with 25 rules & 29.96 & 297.6 & -1.847 & 5.435 & 0.0637 & 0.181 \\
\hline LQI & 29.67 & 291.8 & -3.376 & 4.339 & 0.0118 & 0.146 \\
\hline
\end{tabular}


smooth and without elevations. All in all, the work focuses on the application of mobile robotics in field of agricultural production in terms of impacts of different control algorithms on the consumption of mobile robot devices. The results obtained can serve for selection purposes in cases when the lowest possible operation cost of either mobile robot or autonomous vehicle is required.

\section{Acknowledgments}

This paper was conceived within the project VEGA no. 1/0720/18 Research of Alternative Navigation Algorithms for the Control of Autonomous Robots in Plant Production.

\section{References}

BELOEV, I. - KINANEVA, D. - GEORGIEV, G. - HRISTOV, G. - ZAHARIEV P. 2021. Artificial intelligence-driven autonomous robot for precision agriculture. In Acta Technologica Agriculturae, vol. 24, no. 1, pp. 48-54.

CVIKLOVIČ, V. - OLEJÁR, M. - HRUBÝ, D. - PALKOVÁ, Z. - LUKÁČ, O. HLAVÁČ, P. 2016. Navigation algorithm using fuzzy control method in mobile robotics. In Acta Technologica Agriculturae, vol. 19, no. 1, pp. 19-23.

DIRK-JAN, K. 2011. 2D line curvature and normals. In MATLAB Central File Exchange [online]. [cit. 2020-11-07]. Available at: <https://www.mathworks.com/matlabcentral/ fileexchange/32696-2d-line-curvature-and-normals > .

DUŠEK, F. - HONC, D. - ROZSÍVAL, P. 2011. Mathematical model of differentially steered mobile robot. In Proceedings of $18^{\text {th }}$ International Conference on Process Control, Tatranská Lomnica, Slovakia, pp. 221-229. ISBN 9788022735179.

HRUBÝ, D. - AMRICH, M. 2008. Applications of fuzzy control algorithms in agricultural practice: monograph. Nitra : SUA, 123 pp. ISBN 9788055200538. (In Slovak: Aplikácie fuzzy riadiacich algoritmov $v$ pol'nohospodárskej praxi).

JARAMILLO, M. - DOGRU, S. - GOMEZ-MENDOZA, J. - MARQUES, L. 2020. Energy estimation for differential drive mobile robots on straight and rotational trajectories. In International Journal of Advanced Robotic Systems, vol. 17, no. 2.
JARAMILLO, M. - GÓMEZ MENDOZA，J. 2018. Mixed energy model for a differential guide mobile robot. In $23^{\text {rd }}$ International Conference on Methods \& Models in Automation \& Robotics, New York : IEEE, pp. 114-119. ISBN 9781538643242.

KHATOON, S. - NAZ, K. - NASIRUDDIN, I. 2014. Eigen value analysis of optimal controller design of wheeled autonomous mobile robot. In International Journal of Computer Applications, vol. 103. pp. 13-18.

MARKO, D - HRUBÝ, D. 2020. Distance measuring in vineyard row using ultrasonic and optical sensors. In Proceeding of $22^{\text {nd }}$ International Conference of Young Scientists. Praha : Česká zemědělská univerzita, pp. 194-204. ISBN 9788021330375.

MEI, Y. - LU, Y. - HU, Y. C. - LEE, C. S. G. 2005. A case study of mobile robot's energy consumption and conservation techniques. In Proceedings of $12^{\text {th }}$ International Conference on Advanced Robotics, Seattle, WA, pp. 492-497.

MUNOZ-CEBALLOS, N. - VALENCIA-VELASQUEZ, J. 2014. Benchmark framework for mobile robots navigation algorithms. In Revista Facultad de Ingeniería, vol. 23, no. 36, pp. 6.

STEFEK, A. - PHAM, T. V. - KRIVANEK, V. - PHAM, K. L. 2020. Energy comparison of controllers used for a differential drive wheeled mobile robot. In IEEE Access, vol. 8, pp. 170915-170927.

TOKEKAR, P. - KARNAD, N. - ISLER, V. 2011. Energy-optimal velocity profiles for car-like robots. In 2011 IEEE International Conference on Robotics and Automation, Shanghai, China, pp. 1457-1462.

TÓTH, L. - HRUBÝ, D. - CVIKLOVIČ, V. - OLEJÁR, M. 2017. Algorithms of Autonomous Mobile Robots. Nitra : Slovak University of Agriculture, 132 pp. ISBN 9788055216812.

WANG, Y. - XIONG, W. - YANG, J. - JIANG, Y. - SHUOYU, W. 2019. A robust feedback path tracking control algorithm for an indoor carrier robot considering energy optimization. In Energies, vol. 12, no. 10 , article no. 12102010 . 